\title{
RELATIONSHIP BETWEEN SOCIAL RESPONSIBILITY AND ORGANIZATIONAL IDENTIFICATION OF E-COMMERCE ENTERPRISE BASED ON THE MODERATING EFFECT OF COLLECTIVISM
}

\author{
Linwei $\mathrm{Xu}$ \\ Panyapiwat Institute of Management, Nonthaburi, Thailand
}

This work empirically analyzes the moderating effect of collectivism on the relationship between social responsibility and organizational identification of e-commerce enterprise. Our study suggests that: (1) there would be significant difference on the organizational identification under distinct enterprise sizes, employee gender and educational levels; (2) Fulfillment of duties to employees, consumers and the government has a significant positive impact on organizational identification, while fulfillment of duties to social and non-social stakeholders cannot effectively predict the impact of organizational identification; (3) organizational identification imposes a significant positive effect on the two structural dimensions of organizational citizenship behavior.

Collectivism orientation plays a moderating role in the influence of employee-oriented and government-oriented responsibility on organizational identification. Our study recommends the managers of e-commerce enterprises to strengthen the organic integration of business strategy and corporate social responsibility (CSR), and to develop an effective framework for the system construction of CSR. It is necessary to realize that the fulfillment of corporate social responsibility is a long-term systematic project that requires fullest participation of employees.

Managers should undermine the collectivism orientation of employees, and vigorously activate the interaction between employees and organizations, proactively cultivating the collectivism consciousness and the sense of community among employees.

Keywords: collectivism; corporate social responsibility; organizational identification

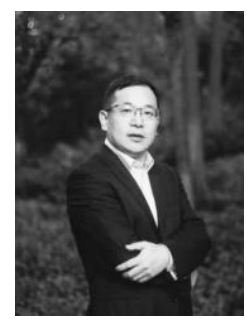

\section{Linwei Xu}

PhD Student, Chinese Graduate School, Panyapiwat Institute of Management, Nonthaburi, Thailand

Research interests: smart city; digital reform; information technologies.

E-mail: zjxlw@126.com 


\section{Introduction}

As a relatively new type of business, e-commerce in China has been showing explosive growth since 2003. However, behind the rapid development of e-commerce business, there are a number of problems emerging, and some existing management weaknesses that need to be addressed.

According to the "Guidance on The Fulfillment of Social Responsibility by Central Enterprises" (China) issued by the State-owned Assets Management Commission of the CPC Central Committee (2008), local governments have formulated and issued detailed regulations and standards to promote enterprises to strictly fulfill their social responsibilities.

For example, the government of Zhejiang Province formulated "Some Opinions on Promoting Enterprises to actively fulfill Social Responsibilities", which details the requirements of environment protection and resource conservation, rights and interests of employees, participation in charity activities and public service for all local enterprises, including e-commerce ones.

Different from Western employees brought up within the environment of Western culture, Chinese employees have their own characteristics:

(1) the cognition of employees over the particularity of the harmony among humans, society and the nature is influenced by the Confucian Culture, however, there are inconsistencies between low sensitivity of employees when it comes to corporate social responsibility (CSR) in real practice and this cognition;

(2) China has the tradition of collectivism, which further reinforces the dependence on groups and the observance of social rules.

As cultural and technological exchanges are becoming more and more extensive and in-depth, the individualism would inevitably affect and change the minds of employees in China, which may render Chinese moral ethical judgment standards in the direction of diversification, thus incurring the complexities of individual characteristics.

Our study pays attention to the problem of whether collectivism orientation plays a moderating role in the influence of different dimensions of CSR on organizational identification. This work may broaden the research results in the realm concerning the influence of CSR on employees' attitudes, effectively exploring the boundary conditions of the intensity of interaction between CSR and employee attitude.

\section{Literature Review and Hypothesis}

According to (Turker, 2009), we divide corporate social responsibility (CSR) into four types:

CSR for society and non-society (e.g., future generations, protection of the natural environment, non-governmental organizations, etc.),

CSR towards own staff,

CSR towards customers/consumers, and finally,

CSR towards government and other public authorities.

In short, we can use CSR-S, CSR-E, CSR-C, CSR-G to denote these four types above. Within the organization, usually, there are two classes of organizational citizenship behaviors (OCB) - individually targeted OCB (OCB-I) and organization-targeted citizenship behavior (OCB-O). 


\section{RELATIONSHIP BETWEEN SOCIAL RESPONSIBILITY}

Different definitions of organizational identification, due to various historical backgrounds, can be classified into three types: emotional definition, cognitive definition, emotional-cognitive hybrid definition. In this paper, organizational identification is defined as "an individual's cognition on the proportion of group or organizational in the self-concept and his/her emotional belonging to the organization in the sense of refuge, pride, etc".

To the best of our knowledge, there has been no research on organizational identification among Chinese academia until the year of 2005. To date, more than 175 corresponding articles have been published in the journals indexed by SCI, EI, CSSCI, PKU. Based on these studies, we may figure out that there are three factors that would affect organizational identification, including organizational factors, external environment factors and individual factors.

Culture is a broad concept, in which the central dimension is often collectivism. Hofstede, the Dutch expert in the field of cross-culture, has put forward five aspect of crosscultural study by tracking the expatriate staff of IBM over 70 countries and regions, namely - uncertainty avoidance, feminism/masculism, power gap, short-term/long-term orientation, collectivism/individualism.

Inspired by this work, many researchers have started continuous studies on the problem of collectivism. Some of these scholars are interested in the mechanism of how collectivism affects the interaction between groups and individuals within an organization. Tab. 1 summarizes the representative definitions of collectivism across various academic circles.

Table 1 - Definitions of Collectivism

(made by the author)

\begin{tabular}{|l|l|}
\hline & \multicolumn{1}{|c|}{ Definition } \\
\hline Wagner et al. (1986) & $\begin{array}{l}\text { A social structure within which individuals tend to work with } \\
\text { other members intra-group; The group objectives, interest } \\
\text { and need are superior to those of an individual. }\end{array}$ \\
\hline Triandis et al. (1988) & $\begin{array}{l}\text { Individuals in the society with collectivist culture submit to } \\
\text { the needs and desires of the group or the organization. }\end{array}$ \\
\hline
\end{tabular}

The study of Wagner et al. (1986) showed that most collectivists in this social structure behave following the rule that the collective interest always comes before the individual interest. Other scholars have offered very similar definitions of collectivism.

Based on the perspective of Wagner et al. (1986), we can define collectivism orientation as the comprehensive cognition of individuals in an organization on the importance of obeying collective interests and following group norms.

In light of the unique characteristics of Chinese culture and the infiltration of Western culture in it, this work introduces Collectivism Orientation (CO) into the analysis, which plays a very important role. On the basis of the insights from Wagner et al. (1986), this paper defines collectivism as follows: "Collectivism refers to the recognition degree of individuals to the collective's obedience and compliance with group norms".

The theory of social relations indicates that an individual (employee) can reduce uncertainty if he/she obtains some resources needed from the social relations he/she belongs to. In the formation of self-concept, individuals with low collectivism orientation prefer to maintain their own unique characteristics. 
However, individuals with high collectivism orientation believe that they should maintain the consistency and close relationship with members of the intra-group.

If the enterprise takes the interest appeal of other parties, besides shareholders (including customers, employees, government, community, and future generations, etc.), it can enhance its social status. Employees would be more concerned about the tendencies of CSR, and thus would generate higher organizational identification.

As a result, this paper proposes the following hypothesis:

Ha: Collectivism orientation positively moderates the influence of CSR-S on employees' organizational identification.

$\mathrm{Hb}$ : Collectivism orientation positively moderates the influence of CSR-E on employees' organizational identification.

Hc: Collectivism orientation positively moderates the influence of CSR-C on employees' organizational identification.

Hd: Collectivism orientation positively moderates the influence of CSR-G on employees' organizational identification.

\section{Empirical Analysis}

\section{Sample Collection}

The samples have been mainly collected from the e-commerce enterprises around Hangzhouand and some other regions in China.

We planned to survey 1,000 employees of over 100 e-commerce enterprises. The respondents have represented employees at all levels of the organization, including general employees and managers of all levels.

We select e-commerce enterprises with various employee scales, with diverse gender, age, length of service, position, and monthly income representation to ensure the representativeness of samples. We have also investigated personal information on the surveyed individuals and the situation of their organizations.

This includes gender (male, female), education (graduate, undergraduate, junior college, and senior high school and below, etc.), position (senior managers, middle managers, first-line managers, staff members, etc.), serving age (11+ years, 6 to 10 years, 4 to 5 years, 2 to 3 years, 1 year or less). We have also taken into account the size of the enterprises (801 employees and above, 501-800 employees, 201-500 employees, 200 employees and below) (Tab. 2).

\section{Sample Processing}

To understand the statistical metrics such as skewness and kurtosis, our study has analyzed the distribution of samples on the basis of the standard proposed by (Huang et al., 2012).

In order to test the effectiveness of the relevant measurement, we have carried out a trial investigation on a small sample prior to the distribution of survey questionnaires to test and analyze the effectiveness of the relevant measurement content. The results of such a trial may help to remove inappropriate measurement items and thus ensure the reliability of the questionnaire contents.

By means of Corrected Item-Total Correlation (CITC), we have been able to identify and delete inappropriate measurement items. Cronbach's coefficient has been adopted to test 


\section{RELATIONSHIP BETWEEN SOCIAL RESPONSIBILITY}

the reliability of the target measurement scale. Afterwards, the absolute skewness and absolute kurtosis of the measurement clauses of the Organizational Identity Scale, Organizational Citizenship Behavior Scale and Corporate Social Responsibility (CSR) scale are no more than 2 and 3, respectively. This implies that the data follows normal distribution, thus ensuring the feasibility of analysis in our study.

Table 2 - Demographic variables of the sample

(made by the author)

\begin{tabular}{|l|l|c|c|}
\hline \multicolumn{1}{|c|}{ Statistical Index } & \multicolumn{1}{|c|}{ Index Value } & Count & Percentage (\%) \\
\hline \multirow{4}{*}{ Gender } & Male & 379 & 51.8 \\
\cline { 2 - 4 } & Female & 353 & 48.2 \\
\hline \multirow{5}{*}{ Age } & $\leq 24$ & 219 & 29.9 \\
\cline { 2 - 4 } & $25-34$ & 401 & 54.8 \\
\cline { 2 - 4 } & $35-44$ & 93 & 12.7 \\
\cline { 2 - 4 } & $45-54$ & 16 & 2.2 \\
\cline { 2 - 4 } & $\geq 55$ & 3 & 0.4 \\
\hline \multirow{5}{*}{ Serving Age } & high school and below & 112 & 15.3 \\
\cline { 2 - 4 } & junior college & 226 & 30.9 \\
\cline { 2 - 4 } & undergraduate & 314 & 42.9 \\
\cline { 2 - 4 } & graduate and above & 80 & 10.9 \\
\hline \multirow{4}{*}{ Position } & $\leq 1$ & 191 & 26.1 \\
\cline { 2 - 4 } & $1-3(3$ included) & 290 & 39.6 \\
\cline { 2 - 4 } & $3-6(6$ included) & 180 & 24.6 \\
\cline { 2 - 4 } & $\geq 6$ & 71 & 9.7 \\
\hline \multirow{3}{*}{ Enterprise Category } & staff & 367 & 50.1 \\
\cline { 2 - 4 } & first-line manager & 246 & 33.6 \\
\cline { 2 - 4 } & middle -senior manager & 119 & 16.3 \\
\hline \multirow{5}{*}{ Enterprise Scale } & state-owned enterprise & 111 & 15.2 \\
\cline { 2 - 4 } & private enterprise & 621 & 84.8 \\
\cline { 2 - 4 } & $\leq 200$ & 302 & 41.4 \\
\cline { 2 - 4 } & $201-500$ & 185 & 25.3 \\
\cline { 2 - 4 } & $501-800$ & 114 & 15.6 \\
\cline { 2 - 4 } & $801-1500$ & 79 & 8.1 \\
\cline { 2 - 4 } & $\geq 1500$ & & \\
\hline & & & \\
\hline
\end{tabular}

Validity Test

In our study, the principal component analysis (PCA) method has been adopted to test the validity. Bartlett's test has been used to determine whether PAC is appropriate.

As illustrated in Tab. 2, all the CITC values of the four dimensions on the CSR scale are acceptable. However, if any item inside the scale is deleted, CITC drops. Therefore, all the items are reserved in our study. The reliability values of CSR-S, CSR-E, CSR-C and CSR-G are 0.873, 0.893, 0.931 and 0.923, respectively (thus, all exceeding 0.7 ). 
Table 3 - CITC Analysis and Reliability Test on the CSR Scale (made by the author)

\begin{tabular}{|c|c|c|c|c|}
\hline $\begin{array}{l}\text { CSR } \\
\text { Type }\end{array}$ & $\begin{array}{c}\text { Measure } \\
\text { Items }\end{array}$ & CITC & $\begin{array}{l}\text { Cronbach's Alpha } \\
\text { with Item Deleted }\end{array}$ & $\begin{array}{c}\text { Cronbach's } \\
\text { Alpha }\end{array}$ \\
\hline \multirow{6}{*}{ CSR-S } & Rs1 & .715 & .844 & \multirow{6}{*}{0.873} \\
\hline & Rs2 & .732 & .841 & \\
\hline & Rs3 & .573 & .868 & \\
\hline & Rs4 & .648 & .856 & \\
\hline & Rs5 & .639 & .858 & \\
\hline & Rs6 & .748 & .838 & \\
\hline \multirow{6}{*}{ CSR-E } & $\operatorname{Re} 1$ & .681 & .879 & \multirow{6}{*}{0.893} \\
\hline & $\operatorname{Re} 2$ & .763 & .867 & \\
\hline & $\operatorname{Re} 3$ & .781 & .863 & \\
\hline & $\operatorname{Re} 4$ & .727 & .872 & \\
\hline & $\operatorname{Re} 5$ & .677 & .880 & \\
\hline & Re6 & .663 & .881 & \\
\hline \multirow{4}{*}{ CSR-C } & Rc1 & .883 & .896 & \multirow{4}{*}{0.931} \\
\hline & $\mathrm{Rc} 2$ & .893 & .892 & \\
\hline & Rc3 & .805 & .921 & \\
\hline & Rc4 & .776 & .930 & \\
\hline \multirow{4}{*}{ CSR-G } & $\operatorname{Rg} 1$ & .763 & .920 & \multirow{4}{*}{0.923} \\
\hline & $\operatorname{Rg} 2$ & .833 & .897 & \\
\hline & Rg3 & .910 & .870 & \\
\hline & $\operatorname{Rg} 4$ & .788 & .912 & \\
\hline
\end{tabular}

\section{Confirmatory Factor Analysis}

The AMOS 20.0 method has been used to perform the confirmatory factor analysis (CFA) on the obtained sample. The fitness of every variable is measured by maximum likelihood estimation method, with the fitting index including two indexes: Chisquare/Degree of Freedom (CMIN/DF), Root Mean Square Error of Approximation (RMSEA). If the values of CFI, GFI, RFI, IFI, etc. are all above 0.90, the model has an excellent fit level. If these index values are higher than 0.70 , the model has a good fitness. Both results are actually acceptable.

Besides, it is also acceptable if PGFI, PNFI and PCFI are all greater than 0.50. The validity test indices are determined according to the results of the confirmatory factor analysis. The more detailed tests on the discriminant validity are performed in terms of standard factor load.

Confirmatory Factor Analysis of the Corporate Social Responsibility (CSR) Scale

Tab. 3 shows the fitting indices, where $C M I N / D F=3.470<5, R M R=0.063<0.08$, $\mathrm{GFI}=0.695$ (that is, almost equal to 0.7 ). 


\section{RELATIONSHIP BETWEEN SOCIAL RESPONSIBILITY}

In addition, the values of IFI, CFI and TLI were $0.910,0.892$ and 0.909 respectively, which were all close to the level of 0.9 and thus achieved excellent fitness. The value of RMSEA is $0.076(<0.08)$, indicating that the fitness of this scale is acceptable.

Table 4 - Goodness of Fit Test of CSR Scale

(made by the author)

\begin{tabular}{|c|c|c|c|c|}
\hline \multirow{2}{*}{ Fit Indices } & \multicolumn{2}{|c|}{ Evaluation Standard } & \multirow{2}{*}{ Value } \\
\cline { 2 - 4 } & CMIN/DF & Good & Excellent & \\
\hline \multirow{4}{*}{} & RMSEA & $<0.08$ & $<3$ & 3.470 \\
\cline { 2 - 5 } & RMR & $<0.08$ & $<0.05$ & 0.076 \\
\cline { 2 - 5 } Fit & GFI & {$[0.70,0.90)$} & $>0.90$ & 0.063 \\
\cline { 2 - 5 } Indices & IFI & {$[0.70,0.90)$} & $>0.90$ & 0.695 \\
\cline { 2 - 5 } & TLI & {$[0.70,0.90)$} & $>0.90$ & 0.910 \\
\cline { 2 - 5 } & CFI & {$[0.70,0.90)$} & $>0.90$ & 0.909 \\
\cline { 2 - 5 } & PNFI & \multicolumn{2}{|c|}{$>0.50$} & 0.739 \\
\cline { 2 - 5 } & PCFI & \multicolumn{2}{|c|}{$>0.50$} & 0.766 \\
\cline { 2 - 5 } & PGFI & \multicolumn{2}{|c|}{$>0.50$} & 0.671 \\
\hline
\end{tabular}

Fig. 1 suggests that the factor load coefficient of all the 20 measurement items in the survey scale exceeds 0.5 . Thus, they are of a significant level, which indicates good fitness and discriminability of the scale.

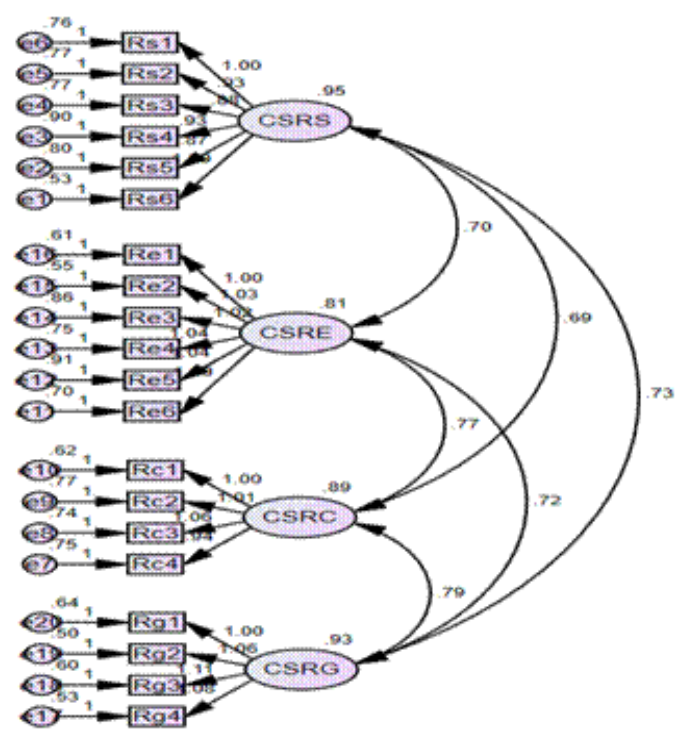

Figure 1 - Confirmatory Factor Analysis of the Corporate Social Responsibility (CSR) Scale (made by the author) 


\section{Confirmatory Factor Analysis of Organizational Identification Scale}

Tab. 5 illustrates the value of fitting indices. The indices including CMIN/DF $(4.241<5)$, RMR $(0.066<0.08)$, GFI $(0.976>0.9)$, all meet the initial fitness requirement. Moreover, the values of IFI, CFI and TLI were $0.965,0.964$ and 0.933 , respectively, therefore, all greater than 0.9 and all achieving excellent fitness.

Meanwhile, the RMSEA value was 0.051 , less than 0.08, thus implying that the fitting level of this scale is acceptable.

Table 5 - Fit Indices Test for the Organizational Identification Scale (made by the author)

\begin{tabular}{|c|c|c|c|c|}
\hline \multicolumn{2}{|c|}{ Fit Indices } & \multicolumn{2}{c|}{ Evaluation Criterion } & \multirow{2}{*}{ Value } \\
\cline { 2 - 4 } & CMIN/DF & Good & Excellent & \\
\hline \multirow{7}{*}{ Fit Indices } & RMSEA & $<0.08$ & $<3$ & 4.241 \\
\cline { 2 - 5 } & RMR & $<0.08$ & $<0.05$ & 0.05 \\
\cline { 2 - 5 } & GFI & {$[0.70,0.90)$} & $>0.90$ & 0.976 \\
\cline { 2 - 5 } & IFI & {$[0.70,0.90)$} & $>0.90$ & 0.965 \\
\cline { 2 - 5 } & TLI & {$[0.70,0.90)$} & $>0.90$ & 0.933 \\
\cline { 2 - 5 } & CFI & {$[0.70,0.90)$} & $>0.90$ & 0.964 \\
\cline { 2 - 5 } & PNFI & \multicolumn{2}{|c|}{$>0.50$} & 0.509 \\
\cline { 2 - 5 } & PCFI & \multicolumn{2}{|c|}{$>0.50$} & 0.514 \\
\cline { 2 - 5 } & PGFI & \multicolumn{2}{|c|}{$>0.50$} & 0.372 \\
\hline
\end{tabular}

This scale is as well of good fitness and discriminability as the factor loading coefficient of the six measurement items are all greater than 0.5 (see Fig. 2).

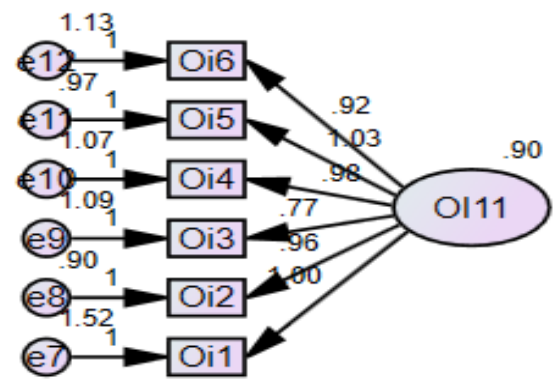

Figure 2 - Confirmatory Factor Analysis of Organizational Identification Scale (made by the author)

\section{Confirmatory Factor Analysis of the Collectivism Orientation Scale}

Tab. 6 illustrates the values of fit indices including CMIN/DF $(1.918<5)$, RMR $(0.057<0.08)$, GFI $(0.975>0.9)$, IFI $(0.965)$, CFI $(0.964)$ and TLI $(0.933)$, all meeting the fitness requirement. Meanwhile, the RMSEA value was 0.071, less than 0.08, thus implying that the fitting level of this scale is also acceptable. 


\section{RELATIONSHIP BETWEEN SOCIAL RESPONSIBILITY}

Table 6 - Fit IndicesTest for the Collectivism Oriented Scale (made by the author)

\begin{tabular}{|c|c|c|c|c|}
\hline \multirow{2}{*}{\multicolumn{2}{|c|}{ Fit Indices }} & \multicolumn{2}{|c|}{ Evaluation Criterion } & \multirow{2}{*}{ Values } \\
\hline & & Good & Excellent & \\
\hline \multirow{10}{*}{ Fit Indices } & CMIN/DF & $<5$ & $<3$ & 1.918 \\
\hline & RMSEA & $<0.08$ & 0.05 & 0.071 \\
\hline & RMR & $<0.08$ & $<0.05$ & 0.057 \\
\hline & GFI & {$[0.70,0.90)$} & $>0.90$ & 0.975 \\
\hline & IFI & {$[0.70,0.90)$} & $>0.90$ & 0.930 \\
\hline & TLI & {$[0.70,0.90)$} & $>0.90$ & 0.836 \\
\hline & CFI & {$[0.70,0.90)$} & $>0.90$ & 0.924 \\
\hline & PNFI & \multicolumn{2}{|c|}{$>0.50$} & 0.563 \\
\hline & PCFI & \multirow{2}{*}{\multicolumn{2}{|c|}{$\begin{array}{l}>0.50 \\
>0.50\end{array}$}} & 0.573 \\
\hline & PGFI & & & 0.408 \\
\hline
\end{tabular}

As can be seen in Fig. 3, the factor load coefficient of the six measurement scales also exceeds 0.5 , and the results are all significant, which indicates that the scale has a good goodness of fit and a high degree of differentiation.

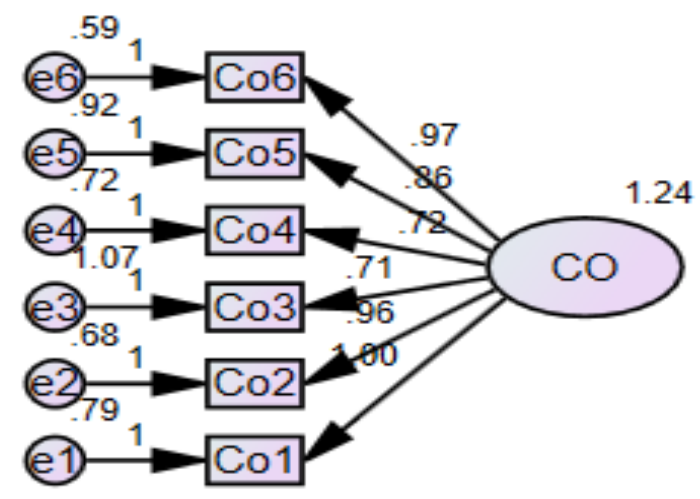

Figure 3 - Confirmatory Factor Analysis for Collectivist Orientation Scale (made by the author)

\section{Hypothesis testing results}

Regression Analysis of Corporate Social Responsibility (CSR) impact on Organizational identification

Taking statistical variables as our control variables, we then carry out a regression analysis on the relationship between the four dimensions of corporate social responsibility (CSR) and organizational identification (see Tab. 6 for details).

The results show that the maximum value of variance inflation factor (VIF) is 2.561 , which is far lower than the threshold of 10. 
Thus, there is no collinearity in this case. The value of Durbin-Watson (DW) index is 1.847, which is close to the standard one (2), thus indicating that there exists no serial correlation.

The R2 value (coefficient of determination) equals to 0.486 here, thus implying the explanatory power of the regression model. The $\mathrm{F}$ value is 61.734 , with the $\mathrm{P}$ value being equal to 0.000 .

Table 7 - Regression of Corporate social responsibility (CSR) to OCB-I (made by the author)

\begin{tabular}{|c|c|c|c|c|c|c|}
\hline \multirow{2}{*}{$\begin{array}{l}\text { Dependent } \\
\text { Variable }\end{array}$} & \multicolumn{2}{|c|}{$\begin{array}{c}\text { Unstandardized } \\
\text { Coefficients }\end{array}$} & \multirow{2}{*}{$\begin{array}{c}\text { Standardized } \\
\text { Coefficients } \\
\text { Beta }\end{array}$} & \multirow{2}{*}{$\mathrm{t}$} & \multirow{2}{*}{ Sig. } & \multirow{2}{*}{$\begin{array}{c}\begin{array}{c}\text { Collinearity } \\
\text { statistics }\end{array} \\
\text { VIF }\end{array}$} \\
\hline & B & $\begin{array}{l}\text { Standard } \\
\text { Error }\end{array}$ & & & & \\
\hline intercept & 1.289 & .246 & & 5.248 & .000 & \\
\hline CSR-S & .050 & .033 & .055 & 1.521 & .129 & 1.831 \\
\hline CSR-E & .207 & .038 & .226 & 5.385 & .000 & 2.455 \\
\hline CSR-C & .183 & .038 & .201 & 4.795 & .000 & 2.461 \\
\hline CSR-G & .258 & .037 & .303 & 7.074 & .000 & 2.561 \\
\hline
\end{tabular}

The Moderating Effect of Organizational Identification between corporate social responsibility (CSR) and $\mathrm{OCB}-\mathrm{O}$

We use a bootstrap model to test and analyze the mediating effect of organizational identification between corporate social responsibility (CSR) and OCB-O, as shown in Table 7.

Model 1 refers to how the independent variable affects the mediating variable.

Model 2 shows the influence of independent variables, intermediary variables, and dependent variables (OCB-O) after the addition of mediating variables. Our mediating analyses control the variables including gender, education background, age, seniority, position, size and type of the enterprise.

As per Tab. 8, organizational identification will not play a mediating role on the relationship between CSR-S and OCB-I or CSR-S and OCB-O.

However, it works either between CSR-E and OCB-I, or between CSR-G and OCB-I. Organizational identification exerts a mediating effect on the correlation between CSR-E, CSR-C, CSR-G and OCB-O. In other words, our initial hypotheses H4b, H4c, H4d, H4f, H4g and $\mathrm{H} 4 \mathrm{~h}$ are supported. However, hypotheses $\mathrm{H} 4 \mathrm{a}$ and $\mathrm{H} 4 \mathrm{e}$ cannot be supported.

\section{Testing the moderating effect of collectivism}

We have applied hierarchical regression analysis to test the moderating effect. Three steps are included in this process:

(1) Model 1: regression of corporate social responsibility (dependent variable) on the recognition (independent variables). As mentioned, there is no significant positive influence of CSR-S on organizational identification. In this section we are paying attention to the other three dimensions (CSR-E, CSR-C, CSR-G); 


\section{RELATIONSHIP BETWEEN SOCIAL RESPONSIBILITY}

(2) Model 2: regression of organizational identification (dependent variables) to CSRE, CSR-C and CSR-G (independent variables) with the collectivist orientation as a regulatory variable;

(3) Model 3-5: Separately taking the cross-product term of independent variables (CSR-E, CSR-C, CSR-G) and a moderating variable (collectivist orientation) into account, running the regression of organizational identification (dependent variables) to the CSR-E (CSR-C or CSR-G) and cross-product term.

Table 8 - The Mediating Effect of Organizational Identification between Corporate Social Responsibility (CSR) and OCB-O

(made by the author)

\begin{tabular}{|c|c|c|c|c|c|c|c|}
\hline $\begin{array}{l}\text { Organizational } \\
\text { Identification }\end{array}$ & \multicolumn{2}{|c|}{ Bootstrap } & $\begin{array}{c}\text { Coeff/Effe } \\
\text { ct }\end{array}$ & $\mathrm{t}$ & $\mathrm{p}$ & LLCI & ULCI \\
\hline \multirow{5}{*}{ CSR-S } & Model 1 & CSR-S & .015 & .465 & .642 & -.048 & .079 \\
\hline & \multirow[t]{2}{*}{ Model 2} & $\begin{array}{l}\text { Organizational } \\
\text { Identification }\end{array}$ & .278 & 7.695 & .000 & .207 & .349 \\
\hline & & CSR-S & .005 & .153 & .878 & -.056 & .066 \\
\hline & \multirow{2}{*}{ Test } & Direct Effect & .005 & .153 & .878 & -.056 & .066 \\
\hline & & Indirect Effect & .010 & & .257 & -.011 & .031 \\
\hline \multirow{5}{*}{ CSR-E } & Model 1 & CSR-E & .140 & 3.612 & .000 & .064 & .217 \\
\hline & \multirow{2}{*}{ Model 2} & $\begin{array}{c}\text { Organizational } \\
\text { Identification }\end{array}$ & .278 & 7.695 & .000 & .207 & .349 \\
\hline & & CSR-E & .081 & 2.116 & .035 & .006 & .156 \\
\hline & \multirow{2}{*}{ Test } & Direct Effect & .081 & 2.116 & .035 & .006 & .156 \\
\hline & & Indirect Effect & .060 & & .000 & .034 & .087 \\
\hline \multirow{5}{*}{ CSR-C } & Model 1 & CSR-C & .160 & 4.220 & .000 & .086 & .235 \\
\hline & \multirow{2}{*}{ Model 2} & $\begin{array}{c}\text { Organizational } \\
\text { Identification }\end{array}$ & .278 & 7.695 & .000 & .207 & .349 \\
\hline & & CSR-C & .109 & 2.924 & .004 & .036 & .182 \\
\hline & \multirow{2}{*}{ Test } & Direct Effect & .109 & 2.924 & .004 & .036 & .182 \\
\hline & & Indirect Effect & .052 & & .000 & .029 & .082 \\
\hline \multirow{5}{*}{ CSR-G } & Model 1 & CSR-G & .244 & 6.728 & .000 & .173 & .315 \\
\hline & \multirow{2}{*}{ Model 2} & $\begin{array}{l}\text { Organizational } \\
\text { Identification }\end{array}$ & .278 & 7.695 & .000 & .207 & .349 \\
\hline & & CSR-G & .171 & 4.739 & .000 & .100 & .242 \\
\hline & \multirow{2}{*}{ Test } & Direct Effect & .171 & 4.739 & .000 & .100 & .242 \\
\hline & & Indirect Effect & .073 & & .000 & .044 & .118 \\
\hline
\end{tabular}

For instance, the demographic variables, CSR-E, organizational identification, the cross term of CSR-E and organizational identification are successively incorporated into the regression function, which is labeled as M3. M4 represents the regression function with CSR-C, while M5 denotes the function with CSR-G.

As shown in Tab. 9, the coefficient of the cross-term in M3 is 0.212, which is significant at the level of 0.01 . Therefore, collectivism orientation imposes a positive 
moderating effect between CSR-E and organizational identification. Similarly, the coefficient of the cross term in M4 is 0.035. Similarly, collectivism orientation produces a positive moderating effect between CSR-C and organizational identification at the significance level of 0.05 . Moreover, the coefficient of the cross term is significant at the level of 0.1 , thus implying that collectivism orientation exerts a positive moderating effect between CSG-C and organizational identification.

Table 9 - Collectivism Orientation and its Moderating Effect (made by the author)

\begin{tabular}{|c|c|c|c|c|c|c|}
\hline \multirow{2}{*}{\multicolumn{2}{|c|}{ Variable }} & \multicolumn{5}{|c|}{ Organizational Identification } \\
\hline & & M1 & M2 & M3 & M4 & M5 \\
\hline \multirow{7}{*}{$\begin{array}{l}\text { Control } \\
\text { Variable }\end{array}$} & Gender & -.076 & -.011 & .067 & .048 & -.007 \\
\hline & Age & .032 & .005 & -.024 & -.020 & .010 \\
\hline & Education & -.045 & -.040 & -.056 & -0.033 & -.067 \\
\hline & Serving Age & .046 & .023 & .017 & .051 & -.010 \\
\hline & Position & .002 & .047 & .087 & .063 & .075 \\
\hline & $\begin{array}{l}\text { Type of } \\
\text { Enterprise }\end{array}$ & $.162 *$ & .096 & .077 & .060 & .081 \\
\hline & Enterprise Size & -.031 & $-.044 *$ & -.058 & -.050 & -.028 \\
\hline \multirow{3}{*}{$\begin{array}{l}\text { Independent } \\
\text { Variable }\end{array}$} & CSR-E & $.245 * * *$ & $.198 * * *$ & $.029 * *$ & & \\
\hline & CSR-C & $.163 * * *$ & $.108 * * *$ & & $.137 *$ & \\
\hline & CSR-G & $.288 * * *$ & $.166^{* * * *}$ & & & 0.088 \\
\hline $\begin{array}{l}\text { Moderating } \\
\text { Variable }\end{array}$ & $\begin{array}{l}\text { Collectivism } \\
\text { orientation }(\mathrm{OI})\end{array}$ & & $.396 * * *$ & $.351 * * *$ & $.310 * * *$ & $0.067 *$ \\
\hline \multirow{3}{*}{ Cross term } & $\mathrm{CSR}-\mathrm{E} * \mathrm{CO}$ & & & $.212 * * *$ & & \\
\hline & $\mathrm{CSR}-\mathrm{C} * \mathrm{CO}$ & & & & $.035 * *$ & \\
\hline & CSR-G $* \mathrm{CO}$ & & & & & $.054 *$ \\
\hline
\end{tabular}

The original sample is modified as per the work values calculated as the mean plus or minus one standard deviation. Then, the employees have been classified into two sub-groups, named as "high work value" and "low work value" according to the mean and standard error of work value (mean \pm standard error). The regressions are then run on every sub-group. In contrast to the low level of collectivism orientation, the effect of CSR-C on organizational identification is notably stronger at the high level. Similarly, the effect of CSR-E on organizational identification is prominently stronger at the high level of collectivism orientation. The effect of CSR-G on organizational identification is enhanced as the collectivism orientation is strengthened.

\section{Conclusions and Insights}

Our study indicates that perception of corporate social responsibility towards employees (CSR-E), towards consumers (CSR-C) and towards government (CSR-G) may actively promote employees' organizational citizenship behavior and organizational commitment. Not only individuals themselves, but also the organization would benefit from such behaviors. More specifically, employees improve their organizational citizenship behavior towards stronger perception on CSR-G and CSR-C. 


\section{RELATIONSHIP BETWEEN SOCIAL RESPONSIBILITY}

Employees' organizational commitment is enhanced as perception of CSR-G and CSRE increases. These insights of ours echo with the conclusions of several former studies.

One of the statement in the social relationship theory suggests that the individual (employee) tends to acquire certain resources from the belonged social relationship to reduce the uncertainty and sustain the sense of security.

Employees with low collectivism orientation usually struggle to maintain their own uniqueness as such. Generally, what they need is neither emotional security, nor social identification. This type of individuals will not care much about the social reputation and/or image of the group or organization they belong to.

Conversely, employees with a high collectivism orientation are more likely to be in need of emotional security and emotional resources from the organization to strengthen their self concept. Our study verifies that high collectivism orientation can have positive effects of corporate social responsibility (CSR) on organization identification.

Based on the weakness of enterprises in fulfilling their social responsibilities and our empirical analysis, we suggest that:

(1) E-commerce enterprises should strengthen the integration of enterprise developing strategy and corporate social responsibility (CSR), and construct an effective framework for CSR system. E-commerce enterprises are suggested to change their somewhat lopsided view on corporate social responsibility. Namely, as of today, their social responsibility is often fulfilled as simply giving away certain amounts of money as donations. It is important to realize that there are various other implementation methods to fulfill their social responsibility as local businesses. E-commerce enterprises should more accurately understand the connotation of CSR and the corresponding benefits inside and outside their organizations, vigorously propagate the significance of CSR fulfillment within enterprises, and proactively cultivating positive energy. It is noteworthy that the attitude and the behavior of top managers have critical significance while cultivating active consciousness of CSR and creating a positive atmosphere for undertaking various CSR projects.

(2) E-commerce enterprises should realize that fulfillment of corporate social responsibility is a long-term and systematic project, involving flow process and solidification, objectives setting, realization approach, and measures of guarantee. Through institutional and systematic operations, enterprises can turn their CSR practices into the rules-based natural behaviors of own employees, thus making CSR integral part of the organizational culture. There are various ways for enterprises to inform employees about what is prohibitive and motivated behavior. Moreover, institutionalization is an important guarantee for cultivating the corporate social responsibility (CSR) culture.

(3) Our results also suggest that employees' participation in corporate social responsibility is the prerequisite for organizational identification. E-commerce enterprises should adequately listen to the voices of their employees, and further reconcile their view. This is the embodiment of the employees' right to be informed and involved. It would be helpful to improve the engagement of employees and promote employees' experiences. Ecommerce enterprises can render the access of employees to the information on how the organization is resorting to various means of information dissemination, (media, socials, etc.). Comprehensive understanding of the organization's status would improve the sensitivity of employees, strengthen their sense of ownership, thus cultivating the sense of the Community of Common Destiny among employees. 
(4) E-commerce enterprises should strengthen the collectivism orientation of their employees and attach more social emotional resources to the practice of CSR, to effectively improve employees' performance in part of organizational citizenship behavior. Inter alia, three procedures are recommended: (i) increasing the effective interaction between employees and the organization, (ii) actively cultivating the collectivism consciousness and the sense of belonging among employees, (iii) formulating and implementing employee career development plans, employee support plans, employee work-family balance plans and other employee assistance plans which can effectively consolidate the collectivism orientation of employees.

\section{References}

Huang, C. C., You, C. S. \& Tsa, M. T. (2012). A multidimensional analysis of ethical climate, job satisfaction, organizational commitment, and organizational citizenship behaviors. Nursing Ethics, 19(4), 513-529.

Triandis, H. C., Bontempo, R., Villareal, M. J., Asai, M. \& Lucca, N. (1988). Individualism and collectivism: Cross-cultural perspectives on self-ingroup relationships. Journal of Personality and Social Psychology, 54, 323-338.

Turker, D. (2009). How corporate social responsibility influences organizational commitment. Journal of Business Ethics, 89,189-204.

Tyler, T. R. (1999). Why people cooperate with organizations: An identity-based perspective. Research in Organizational Behavior, 21, 201-246.

Wagner, J. A. (1995). Studies of individualism-collectivism: Effects on cooperation in groups. Academy of Management Journal, 38(1), 152-173.

Paper submitted

Paper accepted for publishing

Paper published online
15 December 2020

20 January 2021

30 November 2021 